\title{
The role of health and safety experts in the management of hazardous and toxic wastes in Indonesia
}

\author{
Supriyadi ${ }^{*}$, Hadiyanto ${ }^{2}$ \\ ${ }^{1}$ Postgraduate Program of Environmental Science, School of Postgraduate Studies, Diponegoro University, Semarang - Indonesia \\ ${ }^{2}$ Master Program of Environmental Science, School of Postgraduate Studies, Diponegoro University
}

\begin{abstract}
Occupational Safety and Health Experts in Indonesia have an important role in integrating environmental health and safety factors, including in this regard as human resources assigned to undertake hazardous waste management. Comprehensive knowledge and competence skills need to be carried out responsibly, as an inherent professional occupational safety and health profession. Management leaders should continue to provide training in external agencies responsible for science in the management of toxic waste to enable occupational safety and health experts to improve their performance in the hierarchy of control over the presence of hazardous materials. This paper provides an overview of what strategies and competencies the Occupational Safety and Health expert needs to have in embracing hazardous waste management practices.
\end{abstract}

\section{Introduction}

Development as a conscious effort in processing and utilizing resources natural resources to increase the prosperity of the people, both to achieve prosperity and to achieve the inner satisfaction of the increased development activities as an effort to improve the welfare of life always contain the risk of pollution and destruction of the environment, so that the basic structure and function of ecosystems that become life support can be damaged. Therefore, the use of natural resources must be harmonious, harmonious, and balanced with environmental functions.

Hazardous waste is considered to be highly toxic and therefore waste disposal requires the proper management and human resource support in order to reduce the possibility of environmental hazards. The diversity of this type of waste will depend on industrial activity and other waste generators [1].

Starting from the use of raw materials, the selection of production processes and so on will affect the character of waste that can't be separated from the industrial process itself. However, not all industrial waste is a hazardous waste, but only partially. And in fact, as large as hazardous waste does come from industrial activities and should be handled specifically [1-2].

Pollution of the environment itself can be interpreted as an undesirable environmental event, where the occurrence causes disruption or environmental damage and even can lead to health threats until death. Unwanted things that can be called pollution, such as odorless air, cloudy water, land dumped garbage. It can evolve from simply unwanted to interference [2].

The polluted air either by dust, gas or other chemical elements can be painful to the respiratory tract, the eyes become spicy or red and watery. If the contaminant contains hazardous and toxic substances, it may be fatal.

Regulation of the Minister of Manpower of Indonesia no. 2 of 1992 has set out the procedures for the appointment of Occupational Safety and Health Experts. Any company with 100 or more employees, or at high risk of employment, is required to have a safety and health supervisory committee and also a minimum Occupational Safety and Health Expert. Occupational Safety and Health Expert is an extension of the government in overseeing the work of its workplace, in accordance with the requirements of legislation set by the government, thereby reducing the risks and incidents, whether accidents or occupational diseases, including in the case of waste management [3].

Basically every company and labor anywhere does not want accidents, occupational diseases, and environmental pollution. A potential risk of accidents, fires, environmental pollution and occupational diseases may arise due to errors in the use of equipment, lack of information on the work area, and the ability and skills of the less competent workforce [4].

Efforts to enforce occupational safety and health both institutional and work attitude is one way to create a good work area so as to keep the workforce healthy, comfortable, safe and prosperous both during work and after completion of work so that ultimately the level of productivity At the company can reach the highest level. One of the series on examination aspect safety and

Corresponding author: Supriyadi2219@yahoo.com 
health is about Environment and Hazardous and Toxic Waste. Field checks that focus on OSH Environment and Hazardous and Toxic Waste need to be done because it is closely related to the level of awareness of a company on the health of the work area environment [4-5].

Occupational safety and health experts in this case as supervisors recommended by the government, can have a good knowledge of the management of materials waste. So that the impact of pollution and safety can occur well.

The purpose of writing this paper is to provide knowledge to the Occupational Safety and Health experts regarding safety and environmental factors with real practices in the application of requirements and guidance of occupational safety and health in the workplace that includes the conditions and labor facilities, the attitude of the workforce in operating the work equipment, The handling of hazardous chemicals, the nature of the work and the working environment.

\section{Methods}

The principle of hazardous waste management that has been widely discussed in various findings, will be combined with the possibility of optimizing the internal human resources of the company, in this case the role of occupational safety and health experts. Occupational safety and health experts in Indonesia generally have the duty and authority to integrate health, safety and environmental factors. Therefore this important perceived role will be developed more practically for the management of hazardous toxic wastes.

\section{Principles of hazardous waste management in Indonesia}

Understanding of toxic waste according to Law Indonesia no. 32 of 2009 on the Protection and Management of the Environment [5-6]

Article 1 paragraph 21, "Hazardous and toxic material is a substance, energy, and / or other components due to the nature, concentration, and / or amount, either directly or indirectly, can pollute and / or damage the environment, and / or Endangering the environment, health, and the survival of human beings and other living things " [6].

Article 1 verse 22 "Hazardous and toxic waste, hereinafter referred to as B3 Waste, is the remainder of a business and / or activity containing hazardous chemicals"

Article 1, paragraph 23, "Management of toxic waste is an activity that involves the reduction, collection, storage, transport, use, processing, and / or landfill

\subsection{Why Need Toxic Waste Treatment?}

Increased use of hazardous chemicals in various activities, including on industrial activities, mining, energy, oil and gas, health, household and other activities; Increased air pollution control and water pollution control, which will result in dangerous and toxic sludge or dust; significant impacts or pollution caused by toxic waste disposal to the environment;

Indonesia is one of the destination countries for B3 waste disposal; as the implementation of the legislation both the local, national and international (ministerial regulations, local regulations, peraruran government, the Law and the International Convention / Basel Convention).

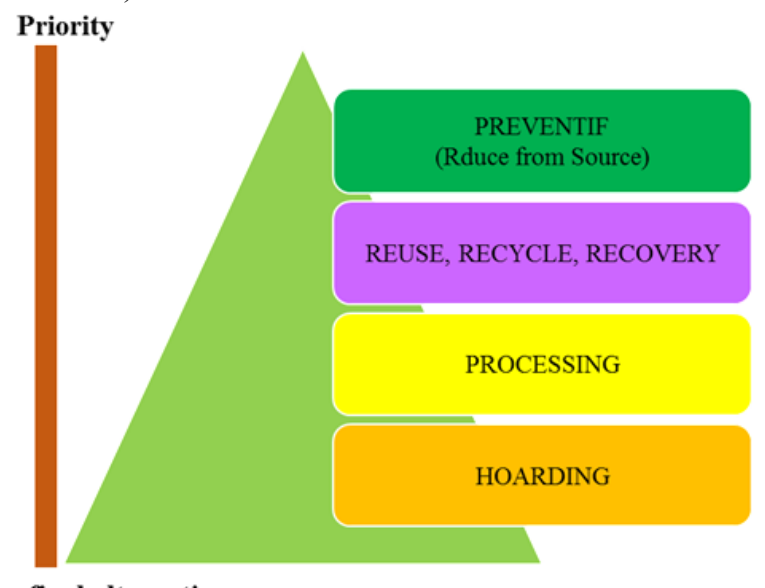

The final alternative

Fig. 1. Hierarchy of hazardous waste management

\subsection{Principles of Hazardous Waste Management}

It is necessary to establish a special type of waste, the criteria of Hazardous Waste, and its management arrangements;

Minimization of Hazardous Waste is a priority;

To minimize risk, the processing should be as close as possible to where the waste will be produced (proximity);

"Polluter pays principle" applies, meaning that anyone who produces Hazardous Waste shall be responsible for managing it;

The principle of monitoring of waste management of Hazardous Waste is "from cradle to grave"

\subsection{Minimization of Hazardous Waste}

Reduction at source;

Substitution of materials, is replacing the use of materials which have the potential to generate Harmful Waste in large quantities and are highly toxic with substances which have the potential to cause Dangerous Waste lower and less toxic and not even toxic;

Arrangement of operation of activities, namely arranging the process of production process in a systematic and planned by considering the selection of production process that can reduce the occurrence of pollution; Application of clean technology; Waste Exchange [7].

Hazardous waste is identified as a chemical with one or more characteristics. According to its nature and character, Hazardous waste is distinguished into: (1) explosive; (2) flammable; (3) reactive; (4) toxic; (5) causes of infection; And (6) are corrosive. While viewed from the source, hazardous wastes are categorized into 3 (three) ie hazardous waste of specific sources, non- 
specific sources, and expired chemicals; spill; Leftover packaging; [7].

Product discharge that does not meet specifications.

1. Explosive waste is defined as waste that through chemical reactions can produce gas with high temperature and pressure that can quickly damage the environment.

2. Flammable waste is waste that when adjacent to a fire, sparks, friction or other ignition sources will be easily ignited or burned and when it has been burning will continue to burn great for a long time.

3. Reactive waste is a waste that causes a fire because it releases or receives oxygen or peroxide organic wastes that are unstable in high temperatures.

4. Toxic waste is a toxic waste that is harmful to humans and the environment. Hazardous waste can cause death or pain when entering the body through respiration, skin or mouth.

5. Waste that causes infection is laboratory waste infected with disease or waste containing germs, such as human body parts amputated and human body fluids infected.

6. Corrosive waste is a waste that causes skin irritation or corrosion of steel, which has a $\mathrm{pH}$ equal to or less than 2.0 for acidic waste and greater than 12.5 for a bias

\subsection{The Nature of hazardous Chemicals in Industries}

Hazardous waste sites pose a multitude of health and safety concerns, any one of which could result in serious injury or death. These hazards are a function of the nature of the site as well as a consequence of the work being performed. They include:

- Chemical exposure.

- Fire and explosion.

- Oxygen deficiency.

- Ionizing radiation.

- Biologic hazards.

- Safety hazards.

- Electrical hazards.

- Heat stress.

- Cold exposure.

-Noise.

Several factors distinguish the hazardous waste site environment from other occupational situations involving hazardous substances. One important factor is the uncontrolled condition of the site. Even extremely hazardous substances do not endanger human health or safety if they are properly handled. However, improper control of these substances can result in a severe threat to site workers and to the general public. Another factor is the large variety and number of substances that may be present at a site. Any individual location may contain hundreds or even thousands of chemicals.

Frequently, an accurate assessment of all chemical hazards is impossible due to the large number of substances and the potential interactions among the substances. In addition, the identity of the substances on site is frequently unknown, particularly in the initial stages of an investigation.

Occupational Safety and Health experts will often be forced to select protective measures based on little or no information. Finally, workers are subject not only to the hazards of direct exposure, but also to dangers posed by the disorderly physical environment of hazardous waste sites and the stress of working in protective clothing [78].

\subsection{Legal Basis of Hazardous Waste Management to be known by Occupational Safety and Health Expert in Indonesia}

Given the importance of processing and utilization of B3 waste, the government considers it necessary to enact legislation to regulate this B3 waste. These rules include:

1. Law Number 32 Year 2009 on Environmental Protection and Management.

2. PP RI Number 18 Year 1999 Jo. PP No. 85/1999 on the Management of Hazardous and Toxic Waste as a revision of PP RI No. 19 of 1994 Jo. PP RI Number 12 of 1995 on Waste Management B3.

3. Kepdal 01 / BAPEDAL / 09/1995 on Technical Procedures and Technical Requirements for Storage and Collection of Waste B3.

4. Kepdal 02 / BAPEDAL / 09/1995 on the B3 Waste Document.

5. Kepdal 03 / BAPEDAL / 09/1995 on Technical Requirements for B3 Waste Treatment.

6. Kepdal 04 / BAPEDAL / 09/1995 on Procedure of Stockpiling of Processing Result, Location Requirement of Former Treatment and Location of B3 Waste Landfill.

7. Kepdal 05 / BAPEDAL / 09/1995 on Symbols and Labels.

8. Kepdal 68 / BAPEDAL / 05/1994 on Procedures to Obtain the B3 Waste Management Permit.

9. Kepdal 02 / BAPEDAL / 01/1998 on the Management of Waste Management of B3.

10. Kepdal 03 / BAPEDAL / 01/1998 on B3 Control Program.

11. Kepdal 255 / BAPEDAL / 08/1996 on Procedures for Storage and Collection of Used Lubricant Oil.

\subsection{Orientation/Education Occupational Safety and Health Expert to Manage Waste Hazardous}

Department Heads are responsible for ensuring that their employees are trained and competent regarding the safe use of the hazardous materials with which they may be working. For employees who have direct contact with hazardous materials and waste this includes precautions for selection, handling, storage, use, and disposal.

They are also instructed about emergency procedures for hazardous material releases and exposures including the health hazards of mishandling hazardous materials and emergency reporting procedures. All new employees attend New Employee Orientation, which includes information regarding hazardous materials and 
hazardous waste safety issues, along with an overview of available resources. In addition, employees' role in maintaining a safe patient care environment is explained.

Every employee is expected to read each Environment of Care section of the Staff Information Handbook and take the posttest, annually. A perfect score is considered passing. Wrong answers are corrected and reviewed with the employee at that time [8].

The Safety routinely conducts Chemical Safety, Hazard Communication and Material Safety Data Sheet training for appropriate departments. In addition, large, open-invitation, hazardous materials seminars are also available as needed. Every employee is given department-specific safety training annually which may include a hazardous materials component, if appropriate. In addition, specific job or area-specific training may be given more frequently to address potential safety hazards associated with the introduction of hazardous materials.

- Training related to Hazardous Chemicals:

- Hazard Communication,

- MSDS Program (HCP)

- Hazardous (Chemical)

- Waste Disposal

- Liquid Nitrogen

- Chemical Spill or Release

- External Hazardous Material

- Release (Toxic Cloud

- Mercury Spill Response Procedures

- Compressed Gas Cylinder

- Transport

- Storage and Use Management of Contaminated Patients

- Cytotoxic Agents

\subsection{Performance Improvement for Occupational Safety and Health Expert to Manage Waste Hazardous}

Performance improvement initiatives are generated from risk assessments, analyses of performance monitoring activities and staff and manager observations and feedback. The primary goal is to provide a safer environment for staff, patients and visitors. 21 Performance improvement projects' selection criteria include their ability to be easily measured, their relevance and statistical validity.

They are also based on risk analysis, quality and effectiveness issues, customer satisfaction, productivity and financial considerations, and regulatory compliance. The process for obtaining measurement data must be reproducible. Reproducible measurement techniques result in advances in quality, productivity, customer satisfaction, cost containment and safety. A threshold level is attached to every performance improvement project. The threshold is the acceptable minimum level of frequency or occurrence. Should an indicator fall below that threshold, the following actions occur:

An investigation is conducted to determine possible reasons for failure to meet or sustain threshold. Based on the findings, a plan for corrective action is developed and implemented.

The standard continues to be monitored to determine if corrective actions were effective in re-establishing threshold. If not, the process is repeated. Each PI indicator is measured on a routine and ongoing basis. If the indicator is an event, then the indicator is measured at each occurrence. If the indicator is monitored consistently over time, then the measurement takes the form of a trend analysis [9].

Performance Monitors are as follows:

- Environmental Rounds results (twice annually)

- Staff Interview results (twice annually)

- Hazardous materials spills and releases (as occur)

- Hazardous materials exposures (as occur)

- Relevant regulatory agency activities (as occur) Respiratory Protection program improvements including medical clearance, initial and annual fit testing. (quarterly)

\section{Conclusions}

Occupational Safety and Health experts as an important element in a company's management play a very strategic role to assist the government in managing hazardous waste. Comprehensive knowledge and competence skills need to be done responsibly, as an inherent professional occupational safety and health profession. Management leaders must continue to provide training in external agencies in charge of science in the management of toxic waste in order to provide opportunities for occupational safety and health experts to improve their performance in the hierarchy of control over the presence of hazardous materials.

\section{References}

1. S. Salhofer, N. Isaac, Environmental Management 30 (1), 68-76, (1999)

2. Gianpaolo Ghiani, Waste Management, Volume 32, Issue 7, Pages 1291-1296, July (2012)

3. Ana Pires,. Journal of Environmental Management, Volume 92, Issue 4, Pages 1033-1050, April (2011)

4. P. Agamuthu, Waste Management and Research 21 (6), 487-497, (2003)

5. Santa Monica, UCLA Medical Center. (2013)

6. S. Salhofer, N. Isaac, Environmental Management 30 (1), 68-76, (1999)

7. Law Number 32 Year 2009 on Environmental Protection and Management. Republic Indonesia (2009)

8. Government Regulation Indonesia Republic Number 18 Year 1999 Jo. PP No. 85/1999 on the Management of Hazardous and Toxic Waste 3. (1999)

9. Mehmet Salim Oncel, Sustainable Environment Research 27 (2017) 188e194. (2017) 